\title{
DETERMINANTS OF GOOD ORAL HYGIENE AMONG PREGNANT WOMEN IN IBADAN, SOUTH-WESTERN NIGERIA.
}

\author{
Joy U. Ifesanya, Adeleke O. Ifesanya, Michael C. Asuzu, and Gbemisola A. Oke
}

\author{
Correspondence: \\ Dr. Joy U. Ifesanya \\ Department of Child Oral Health \\ University College Hospital, \\ Ibadan \\ E-mail: joyifesanya@yahoo.co.uk \\ Telephone: +2348055623129
}

\begin{abstract}
Background and objectives: The need to attain and maintain good oral hygiene among pregnant women cannot be over emphasized as periodontal diseases in pregnancy have been linked with poor pregnancy outcomes. This study assessed the variables that affect oral hygiene status among pregnant women in a south-western Nigerian locality.

Methodology: Four hundred and five pregnant Nigerian women were assessed for their oral hygiene status using the Oral Hygiene Index-Simplified. Demographic and pregnancy statistics were also obtained and the relationships between these and oral hygiene status were determined.

Results: The mean age was $25.35 \pm 5.02$ years. Most of the women $\mathbf{( 9 6 . 0 \% )}$ had never visited a dentist or any other oral health care provider and only $12.5 \%$ of those who had been attended by dental care givers have ever had professional dental cleaning. The oral hygiene status appeared to worsen as parity increased $(p=0.047)$ while the use of the toothbrush and paste was associated with good oral hygiene $(p=0.007)$. Higher education was associated with use of the tooth brush and paste $(\mathrm{p}=0.046)$ and good oral hygiene $(\mathrm{p}=$ 0.001).

Conclusion: The positive effect of education on oral hygiene practices is highlighted in this study. However there is still need for proper health enlightenment in this population with regards to use of the available oral health care facilities.
\end{abstract}

Keywords: Oral hygiene, Pregnancy, Nigeria.

\section{INTRODUCTION}

Previous reports have documented a high prevalence of gingivitis among pregnant women. ${ }^{1,2}$ Some of these reports have associated the occurrence of periodontal diseases in pregnant women with an increased risk for poor pregnancy outcome. ${ }^{3,4}$ Physiologic changes such as pregnancy alter women's body response to external stimuli. In the mouth, the greatest effect of pregnancy is seen in the gums. The main cause of gingivitis both in the pregnant and non- pregnant state is dental plaque, a soft creamy film which is adherent to the teeth and houses the majority of between 300 to 500 different bacterial species found in the mouth. ${ }^{5}$ The higher concentration of oestrogen and progesterone during pregnancy especially in the presence of plaque have been implicated in the pathophysiology of pregnancy gingivitis. Plaque starts building up immediately after tooth-brushing ${ }^{6}$, thus, daily oral cleansing helps to keep this biofilm under control ${ }^{5}$ and enhance good oral hygiene.

The possibility that many women go through their pregnancies without giving consideration to their oral health status while they are bombarded with health talks on other aspects of health at every ante-natal visit leaves much to be desired ${ }^{7}$. Reports have shown that women are more likely to use dental services in pregnancy if they were married, educated, had dental insurance, previously used dental services when not pregnant, or had knowledge about the possible connection between oral health and pregnancy outcome $^{8}$. The purpose of this study was to explore the factors determining good oral hygiene among pregnant women in a South- western Nigerian locality.

\section{METHODOLOGY}

Ethical approval was obtained from the State Ethical Review Board. Interviewer-administered questionnaires were used to obtain demographic data, pregnancy and social history, oral hygiene practices and history of professional dental care from pregnant women who were consecutive attendees at two primary health care ante-natal clinics in a local government area within a municipality in south western Nigeria over a period of six (6) weeks. Each woman had an intra-oral 


\begin{tabular}{|c|c|c|c|c|}
\hline \multirow[t]{2}{*}{ Variable } & \multicolumn{2}{|c|}{ Oral hygiene status } & \multirow[t]{2}{*}{ Total } & \multirow[t]{2}{*}{ P-value } \\
\hline & Good oral hygiene & Fair oral hygiene & & \\
\hline \multicolumn{5}{|l|}{ Parity } \\
\hline Primiparous & $57(45.2)$ & $69(54.8)$ & $126(100.0)$ & \\
\hline Multiparous & $98(31.8)$ & $159(61.9)$ & $257(100.0)$ & $\begin{array}{l}\text { Chi } \mathrm{sq}=6.124 ; \mathrm{df}=2 \\
\mathrm{p}=0.047\end{array}$ \\
\hline Grandmultiparous & $4(18.2)$ & $18(81.8)$ & $22(100.0)$ & \\
\hline Total & $159(39.3)$ & $246(60.7)$ & $405(100.0)$ & \\
\hline \multicolumn{5}{|l|}{ Trimester } \\
\hline First \& second & $43(40.6)$ & $63(59.4)$ & $106(100.0)$ & \\
\hline Third & $116(38.8)$ & $183(61.2)$ & $299(100.0)$ & $\begin{array}{l}\text { Chi sq .103; df }=1 ; \\
\mathrm{p}=0.748\end{array}$ \\
\hline Total & $159(39.3)$ & $246(60.7)$ & $405(100.0)$ & \\
\hline \multicolumn{5}{|l|}{ Brushing implement } \\
\hline Toothpaste \& brush & 150 (41.6) & $211(58.4)$ & $361(100.0)$ & \\
\hline Chewing stick \& others & $9(18.6)$ & $35(81.4)$ & $43(100.0)$ & \multirow[t]{2}{*}{$\begin{array}{l}\text { Chi sq. } 10.035 ; \mathrm{df}=1 \mathrm{p}= \\
0.007\end{array}$} \\
\hline Total & $159(39.3)$ & $246(60.7)$ & $405(100.0)$ & \\
\hline
\end{tabular}

Table 1: Relationship between clinical variables, brushing implement and oral hygiene status

examination with a mirror and periodontal probe which was conducted by the first author, under natural light with particular attention to their oral hygiene and gingival health status. The Oral Hygiene Index (Simplified) of Green and Vermillion (1960) was used as a measure of oral hygiene, while the Gingival Index of Löe and Silness (1963)y was used as a measure of gingival health. The data obtained were entered into a computer spread sheet and analyzed using the Statistical Package for Social sciences (SPSS) version 17. Frequency tables and measures of central tendency were generated and statistical relationships were obtained using the Chi-square test. Binary logistic regression analysis was carried out on variables that had statistically significant effect on the oral hygiene status of the women to determine which specific groups were significant predictors of good oral hygiene.

\section{RESULTS}

A total of four hundred and five (405) pregnant women were studied. Their ages ranged between 13 to 41 years, (mean $25.35 \pm 5.02$ years). Ninety-six percent of the women were married. Figure 1 shows the highest education attained by the respondents. About $59.8 \%$ of the women had secondary school education, $36 \%$ had primary school education. Less than $2 \%$ had post secondary education while the rest were uneducated. Only $1.2 \%$ of the women were professionals by occupation.

Two hundred and sixty-seven women (66.2\%) brushed their teeth once daily, while a hundred and thirty-two (33.8\%) reported brushing twice a day. The most commonly used brushing implement was the toothbrush and paste $(89.1 \%)$. While $43(10.6 \%)$ used chewing sticks, one person cleaned her mouth with cotton-wool and salt. Most of the women (96.0\%) 
had never visited a dentist or any other oral health care provider in their life. Of the total of 16 women who had been attended to by dental professionals, 12 $(75 \%)$ were for toothache, while two each $(12.5 \%)$ were for management of trauma and professional dental cleaning.

The mean oral hygiene score was $1.3 \pm 0.5$. One hundred and fifty-nine $(39.3 \%)$ of the women had good oral hygiene while the rest had moderate accumulation of plaque and calculus though one person had poor oral hygiene. The mean gingival score was $1.2 \pm 0.3$. The prevalence of gingivitis among the women studied was $100 \%$. While $37.5 \%$ had mild gingivitis, $62.5 \%$ had moderate form of the disease and there was one implements $(p=0.007)$ table 1 . Neither the frequency of tooth brushing nor the use of professional dental care significantly influenced oral hygiene status ( $p=0.794, p=0.503$ respectively). Table 2 shows that there was no significant association between oral hygiene status and socio-demographic factors of age, marital status, occupation and religion. The only sociodemographic factor that significantly affected the oral hygiene status of the women in this study was the level of education as it was observed that women with secondary and post-secondary education had better oral hygiene than those with primary or no education $(p<0.001)$. The more educated women were more likely to use the tooth brush and paste $(p=0.046)$ Table 3. Binary logistic regression analysis of all variables that

\begin{tabular}{|c|c|c|c|c|}
\hline \multirow{2}{*}{$\begin{array}{l}\text { Variable } \\
\text { Age (years) }\end{array}$} & \multicolumn{2}{|c|}{ Oral hygiene group } & \multirow[t]{2}{*}{ Total N (\%) } & \multirow[t]{2}{*}{$\mathrm{C}$ hi square, $\mathrm{P}$ value } \\
\hline & $\begin{array}{l}\text { Good oral hygie ne } \\
\mathrm{n}(\%)\end{array}$ & $\begin{array}{c}\text { Fair o ral hygiene } \\
\mathrm{n}(\%)\end{array}$ & & \\
\hline $11-20$ & $37(45.7)$ & $44(54.3)$ & & \\
\hline $21-30$ & $107(38.6)$ & $170(61.4)$ & & \\
\hline$>30$ & $15(31.9)$ & $32(68.1)$ & $81(100.0)$ & \\
\hline Total & $159(39.3)$ & $246(60.7)$ & $\begin{array}{r}277(100.0) \\
47(100.0) \\
405(100.0)\end{array}$ & $\begin{array}{l}\mathrm{X}^{2}=0.509, \mathrm{df}=2 ; \\
\mathrm{p}=0.285\end{array}$ \\
\hline Occupation & $144(39.6)$ & $174(60.5)$ & & \\
\hline Unskilled workers & $34(39.5)$ & $52(60.5)$ & & \\
\hline Skilled workers and & & & $288(100.0)$ & \\
\hline professionals & $11(35.5)$ & $20(64.5)$ & $86(100.0)$ & $\mathrm{X}^{2}=0.201, \mathrm{df}=2$ \\
\hline Unem ployed & & & & $\mathrm{p}=0.905$ \\
\hline Total & & & $31(100.0)$ & \\
\hline Marital status & $5(38.5)$ & $8(61.5)$ & $405(100.0)$ & \\
\hline Single & $154(39.3)$ & $238(60.7)$ & & \\
\hline Married & $159(39.3)$ & $246(60.7)$ & $13(100.0)$ & $\mathrm{X}^{2}=0.597, \mathrm{df}=1$ \\
\hline Total & & & $392(100.0)$ & $p=0.952$ \\
\hline R eligion & $36(46.8)$ & $41(53.2)$ & $405(100.0)$ & \\
\hline Christian & $123(37.5)$ & $205(62.5)$ & & \\
\hline Islam & $159(39.3)$ & $246(60.7)$ & $77(100.0)$ & \\
\hline Total & & & $328(100.0)$ & $\mathrm{X}^{2}=2.239, \mathrm{~d} \mathrm{f}=1 ;$ \\
\hline Level of education & $43(29.5)$ & $103(70.5)$ & $405(100.0)$ & $\mathrm{p}=0.135$ \\
\hline Prim ary school & $109(45.0)$ & $133(55.0)$ & & \\
\hline Secondary school & $5(71.4)$ & $2(28.6)$ & $146(100.0)$ & \\
\hline Post secondary & $2(20.0)$ & $8(80.0)$ & $242(100.0)$ & $\mathrm{X}^{2}=13.875 ; \mathrm{df}=3$; \\
\hline No education & $159(100.0)$ & $246(100.0)$ & $7(100.0)$ & $\mathrm{p}<0.001$ \\
\hline Total & & & $10(100.0)$ & \\
\hline & & & $405(100.0)$ & \\
\hline
\end{tabular}

Table 2: Relationship between socio-dem ographic variables and oral hygiene

severe case of gingivitis among the women. The severity of gingivitis was dependent on oral hygiene status $(\mathrm{p}<0.001)$.

The oral hygiene status appeared to worsen as parity increased $(p=0.047)$. However, the relationship between the oral hygiene status of the women and the trimester of pregnancy was not statistically significant $(p=0.748)$. It was observed that those who used the toothbrush and paste had better oral hygiene than those who used the chewing sticks or other tooth brushing significantly affected oral hygiene status showed that the likelihood that women with greater than four children will have good oral hygiene compared to those about to have their first child and those with 2-4 children was 0.47 and 0.56 respectively (i.e. less than 1). These relationships were not statistically significant $[\mathrm{p}=0.22(\mathrm{C} . \mathrm{I}=0.140-1.555)$ and 0.33 (C.I $=0.174$ 1.793) respectively]. 


\begin{tabular}{|c|c|c|c|}
\hline \multirow[t]{2}{*}{ Level of education } & \multicolumn{2}{|c|}{ Brushing implement } & \multirow[t]{2}{*}{ Total $(\%)$} \\
\hline & Toothbrush \& paste $(\%)$ & Chewing stick \& others (\%) & \\
\hline Primary school & $125(85.6)$ & $21(14.4)$ & $146(100.0)$ \\
\hline Secondary school & $223(92.1)$ & $19(7.9)$ & $242(100.0)$ \\
\hline Post secondary & $6(85.7)$ & $1 \quad(14.3)$ & $7(100.0)$ \\
\hline No education & $7(70.0)$ & $3(30.0)$ & $10(100.0)$ \\
\hline Total & 361 (89.1) & $44 \quad(10.9)$ & $405(100.0)$ \\
\hline
\end{tabular}

Chi $s q=8.002 d f=3 ; p=0.046$

Table 3: Relationship between level of education and type of brushing implement

The likelihood of women with no education having good oral hygiene than the comparatively better educated women was less than one [ 0.80 for primary education, $\mathrm{p}=0.79$ (C.I $=0.154-4.117) ; 0.45$ for secondary school education, $\mathrm{p}=0.34$ (C.I $=0.087$ 2.301); and 0.14 for post secondary school education $\mathrm{p}=0.09$ (C.I $=0.014-1.445)]$. Overall, the level of education was a significant predictor of good oral hygiene $(\mathrm{p}=0.028)$.

The likelihood of having good oral hygiene among chewing stick users compared to those using the tooth brush and paste was 0.42 and this was statistically significant $(p=0.03$ C.I $=0.191-0.921)$.

\section{DISCUSSION}

Only a third of the subjects in this study brushed twice daily though higher values are reported from non-
African studies ${ }^{1-8}$. This may be a result of the low level of dental education and awareness in this environment. Reports have shown that regular tooth-brushing reduces the formation of dental plaque ${ }^{5-6}$. The use of adjuvant cleaning devices such as the dental floss was not investigated in this study although daily use of this implement has also been shown to positively influence oral hygiene status ${ }^{11-12}$. Unlike findings from other studies ${ }^{1-8}$, only $4 \%$ of the study population had ever been to the dentist and $0.49 \%$ had ever had a scaling and polishing done. This is far from ideal and may be responsible for the high prevalence of gingival inflammation seen in these women as significant relationship between use of professional dental services and the plaque index in pregnant women has been reported ${ }^{12}$. Considering the above statistics, it is surprising that only one of the women had poor oral hygiene or severe gingivitis.

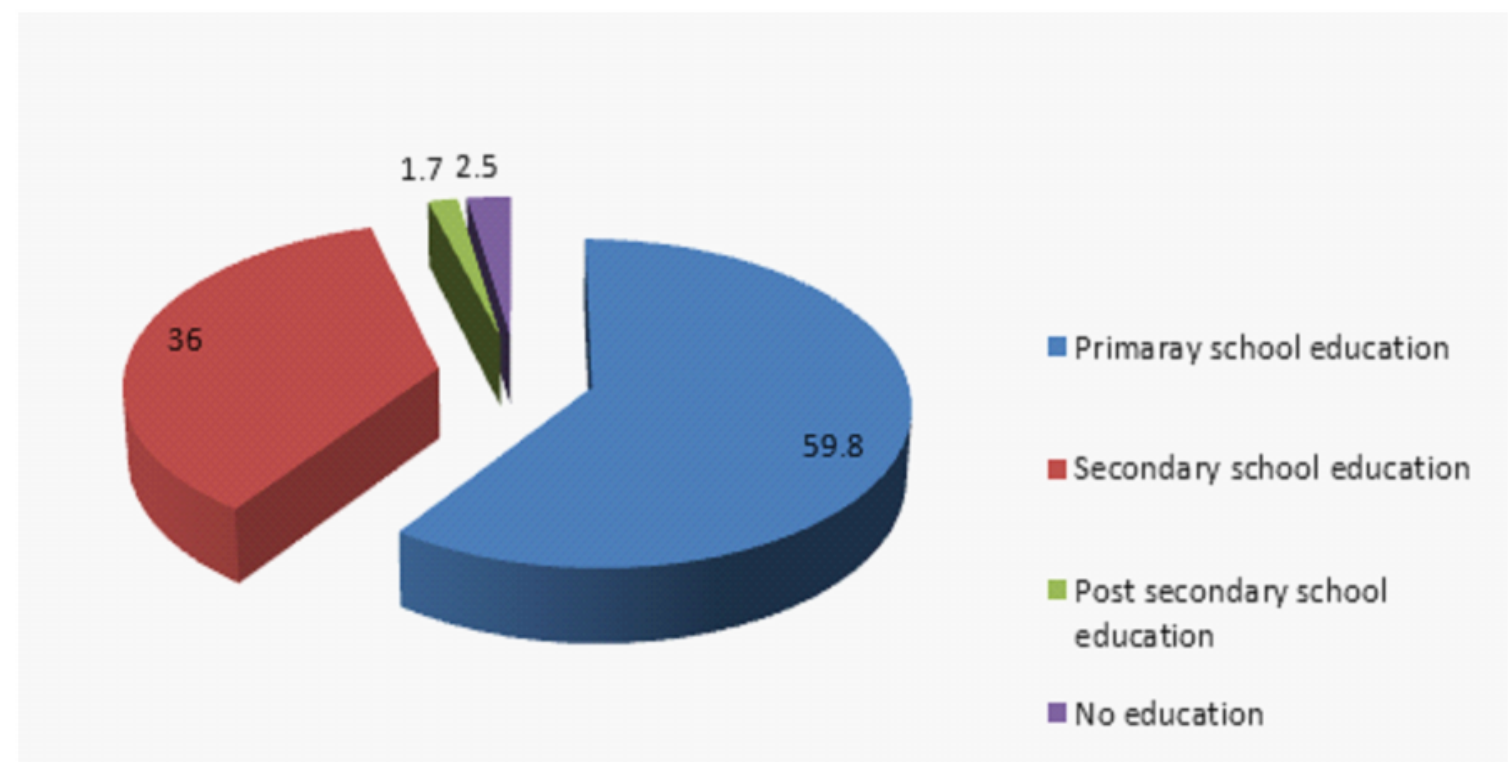

Fig 1. Distribution of the women studied by educational status 
The additional fact that the frequency of brushing did not significantly affect oral hygiene or severity of gingivitis in these women calls to question the effectiveness of their tooth-brushing technique especially among those who brushed twice daily. It is expected that brushing twice daily should improve the oral hygiene ${ }^{10}$ and thus reduce the severity of disease if present at all: provided that effective tooth-brushing methods are used ${ }^{13-14}$. Our finding in this regard however questions the effectiveness of brushing techniques in this environment. Using the toothbrush and tooth paste significantly improved the oral hygiene of the women as compared to the use of other implements in accordance to established literature. This is probably because most people in the study environment chew on rather than brush their teeth with the chewing stick which was the other popular tooth brushing implement $t^{13-14}$.

The oral hygiene of the women also significantly improved as their level of education increased and this is similar to previous findings ${ }^{12-15}$. It is known that the more educated an individual, the more likely he or she is to develop wellness behaviour and utilize health care services ${ }^{16 .}$ Also, well educated women are likely to have fewer children than the less educated and good education is associated with better standard of living. This is added impetus to striving for better education especially of the girl child. Binary logistic regression showed that the level of education was a significant predictor for good oral hygiene among the women in this study though a specific educational background could not be linked to this association and this may be due to the low percentage of women with post secondary school education. The type of brushing implement was also a significant predictor of good oral hygiene.

The oral hygiene status of the women progressively worsened as parity increased, a finding which differed from a Spanish report which found no significant relationship between oral hygiene and parity ${ }^{12}$. The above finding may be a result of the stress of running the home, taking care of children and business, compounded by the stress of pregnancy, with attendant neglect of proper personal and oral hygiene measures. However, knowing that parity increases with age, the relationship between age and oral hygiene status was sought and it was not significant. Binary logistic regression also showed that parity was not a good predictor of good oral hygiene and further studies are required in this regard as none was found which compared the oral hygiene status of nulliparous women against those who had children.
Unlike findings from other studies ${ }^{12-15}$, the use of professional dental care did not significantly affect the oral hygiene status of the women. Because of the small number of women in this category, it is impossible to draw conclusions from this analysis.

Higher education was associated with use of the tooth brush and this may have been a confounding effect on the significant relationship between type of brushing implement and oral hygiene.

\section{CONCLUSION}

This study has highlighted education as a good predictor of good oral hygiene and coroborates the fact that education improves health seeking behaviors. The use of professional oral health care facilities in pregnancy needs to be improved by means of collaborations between oral health care and ante-natal health care givers.

\section{REFERENCES}

1. Christensen LB, Jeppe-Jensen D and Petersen PE. Self-reported gingival conditions and self-care in the oral health of Danish women during pregnancy. J Clin Periodontol. 2003; 30(11):94953.

2. Barak S, Oettinger-Barak O, Oettinger Matchei EM et al. Common oral manifestation during pregnancy: a review. Obstet Gynecol. Surv. 2003; 58(9):624-628.

3. Lopez NJ, Smith PC and Gutierrez J. Higher risk of pre-term and low birth weight in women with periodontal disease. J Dent Res. 2002; 81(1):5863.

4. Marin C, Segura-Egea JJ, Martinez-Sahuquillo Á and Bullon P. Correlation between infant birth weight and mother's periodontal status. J Clin Periodontol 2005; 299-304.

5. Jin LJ, Chiu GKC and Corbet EF. Are periodontal diseases risk factors for certain systemic disorders? - What matters to medical practitioners. Hong Kong Med J. 2003; 9:31-37.

6. Eley BM and Manson JD. The effect of systemic factors on the periodontal tissues. Periodontics. $5^{\text {th }}$ edition. Elsevier Limited. Toronto 2004; P 90-91.

7. Alwaeli HA and Al-Jundi SH. Periodontal disease awareness among pregnant women and its relationship with socio-demographic variables. Int J Dent Hyg. 2005; 3(2):74-82. 
8. Habashneh R, Guthmiller JM, Levy S, et al. Factors related to utilization of dental services during pregnancy. J Clin Periodontol 2005; 32: $815-821$.

9. Löe $\mathbf{H}$ and Silness J. Periodontal disease in pregnancy. Acta Odontol Scand 21:533, 1963.

10. Casamassimo $\mathbf{P}$ and Holt K, (eds.) 2004. Bright Futures in Practice: Oral Health-Pocket Guide. Washington, DC: National Maternal and Child Oral Health Resource Center.

11. E1-Qaderi SS and Ta'ani DQ. Assessment of periodontal knowledge and periodontal status of an adult population in Jordan. Int J Dent Hygiene. 2004; 132-136.

12. Machuca G, Khoshfiez O, Lacalle JR, Machuca $\mathrm{C}$ and Bullon P. The influence of general health and socio-cultural variables on the periodontal condition of pregnant women. J Periodontol 1999; 70 (7): 779-785.
13. Aderinokun GA, Lawoyin JO and Onyeaso CO. Effect of two common Nigerian chewing sticks on gingival health and oral hygiene. Odontostomatol Trop 1999; 22(87):13-18.

14. Al- Otaibi M, Al- Harthy M, Gustafsson A, et al. Subgingival microbiota in Saudi-Arabians after use of Miswak chewing stick and toothbrush. J Clin Periodontol 2004; 31: 1048-1053.

15. Yalcin F, Eskinazi E, Soydinc M, et al. The effect of socio-cultural status on periodontal conditions in pregnancy. J periodontol 2002; 73:178-182.

16. Sohn W, Ismail A, Amaya A and Lepkowski J. Determinants of dental care visits among lowincome African-American children. J Am Dent Assoc, 2007; 138(3):309-318. 